\title{
THEMIS observations of earthward convected flux ropes triggering field dipolarization/substorm expansion and associated particle energization
}

\author{
I. I. Vogiatzis ${ }^{1,2}$, O. E. Malandraki ${ }^{3}$, Q.-G. Zong ${ }^{1,7}$, X.-Z. Zhou ${ }^{4}$, T. E. Sarris ${ }^{2}$, E. T. Sarris ${ }^{2}$, H. Zhang ${ }^{5}$, and \\ T. A. Fritz \\ ${ }^{1}$ Institute of Space Physics and Applied Technology, Peking University, Beijing, China \\ ${ }^{2}$ Department of Electrical and Computer Engineering, Democritus University of Thrace, Xanthi, Greece \\ ${ }^{3}$ Institute of Astronomy and Astrophysics, National Observatory of Athens, Athens, Greece \\ ${ }^{4}$ Institute of Geophysics and Planetary Physics, University of California, Los Angeles, CA, USA \\ ${ }^{5}$ Physics Department and Geophysical Institute, University of Alaska Fairbanks, Fairbanks, AK, USA \\ ${ }^{6}$ Center for Space Physics, Department of Astronomy, Boston University, Boston, MA, USA \\ ${ }^{7}$ Center for Atmospheric Research, University of Massachusetts Lowell, Lowell, MA, USA
}

Received: 20 April 2011 - Revised: 5 November 2011 - Accepted: 7 November 2011 - Published: 24 November 2011

\begin{abstract}
We investigated a number of substorm events during major conjunctions of the THEMIS spacecraft for the tail seasons of the mission. We present simultaneous observations from various instruments onboard the THEMIS spacecraft during the events. We focus particularly on events when at least one of the THEMIS spacecraft is adjacent to the neutral sheet where convectional plasma flows are observed. The events demonstrate clear dipolarization signatures accompanied by high-speed earthward plasma flows and intense wave activity. We present evidence that flux ropes are embedded within the high-speed earthward convective plasma sheet flows. This fact has important implications since the leading edge of the flux rope having south polarity can impulsively merge with the north polarity field of the stretched magnetotail leading to mutual erosion of both magnetic structures. The merging of the vertically oriented oppositely-directed field lines can lead to local cross-tail current reduction and flux rope dissipation. These observations are very important in explaining the mechanism triggering near-Earth dipolarization and particle acceleration to supra-thermal energies, since they can be associated with non-adiabatic conditions and breakdown of the frozen-in condition in the near-Earth magnetotail similar to that taking place during magnetic reconnection in the mid-tail.
\end{abstract}

Keywords. Magnetospheric physics (Storms and substorms)

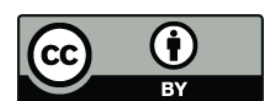

Correspondence to: I. I. Vogiatzis (ivogiatz@ee.duth.gr)

\section{Introduction}

The mechanism that triggers substorm expansion onset remains an unsolved issue and a longstanding debate for magnetospheric scientists. The two models that are the most popular and manage to explain many of the observational substorm features are the current sheet disruption (CD) model (Lui, 1996) and the near-Earth neutral line model (NENL) model (Baker et al., 1996). In the current disruption model the neutral sheet stability is disrupted by local kinetic instabilities (Lui et al., 1990, 1991, 1992; Lui, 2004), leading to dipolarization and current wedge formation. In NENL model magnetic reconnection (MR) plays a pivotal role in the region between 20-30 Earth radii downtail by producing convective earthward bursty bulk flows. These earthward convective flows, in turn, transfer magnetic flux and energy towards the Earth (Angelopoulos et al., 1994, 1996) producing intense field-aligned currents (Shiokawa et al., 1997; Birn et al., 1999; Zhang et al., 2007), directed into the ionosphere which are then responsible for auroral brightening.

During plasma convection in the magnetotail several magnetic structures can be detected. The three most common types of magnetic structures generated by reconnection in the magnetotail are: dipolarization fronts (DFs), flux ropes, and travelling compression regions. In our study we are interested in DFs and flux ropes.

DFs are a common feature of substorm dynamics and are the result of magnetic field pileup (Hesse and Birn, 1991) in the near-Earth region closely related to reconnection-driven bursty bulk flows (BBFs) (e.g. Nakamura et al., 2001). This

Published by Copernicus Publications on behalf of the European Geosciences Union. 


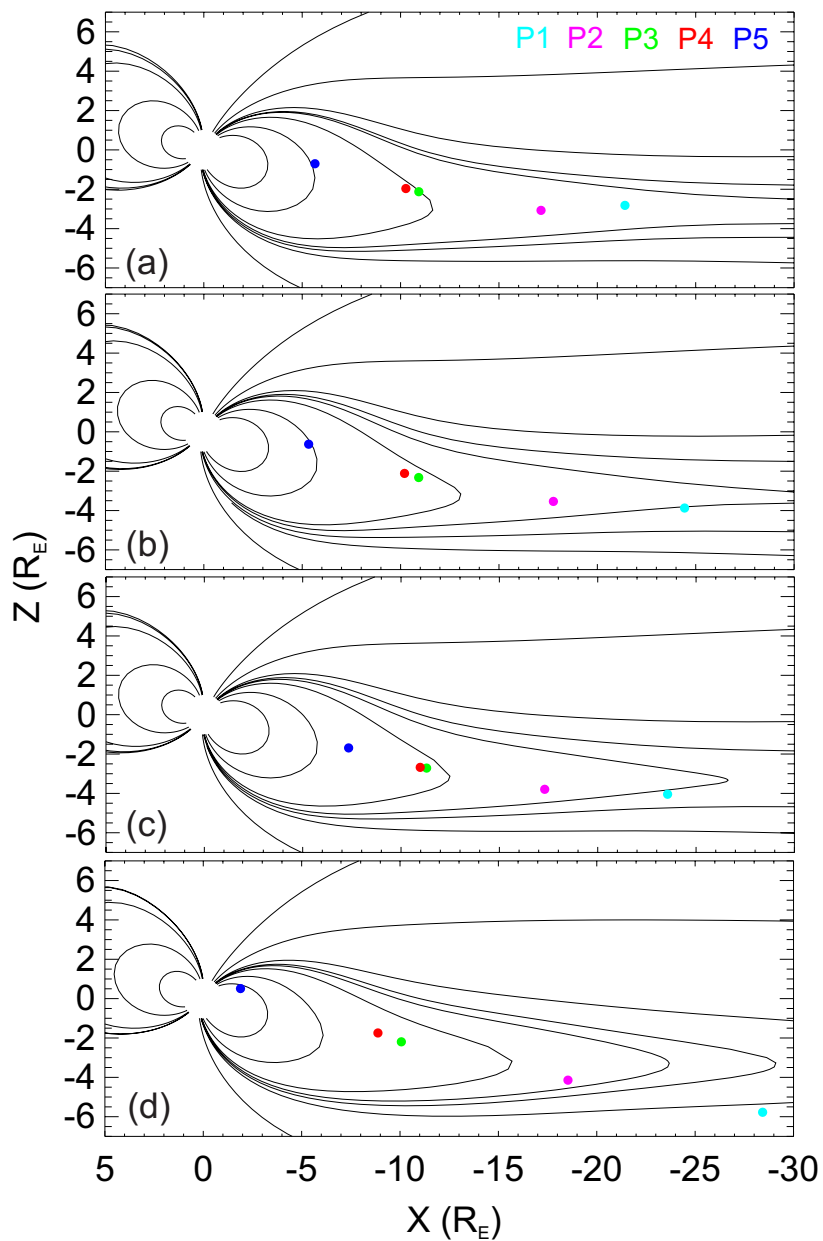

Fig. 1. Positions of the five THEMIS spacecraft for the four events presented in the GSM xz plane: (a) 26 February 2008, 04:53 UT, (b) 22 February 2008, 04:37 UT, (c) 22 February 2008, 06:26 UT, and (d) 14 February 2008, 02:44 UT. Also shown are the superimposed magnetic field lines obtained from the T96 model (Tsyganenko, 1995).

particular feature lasts only a few seconds and it is characterized by a large increase in the $B_{\mathrm{Z}}$ magnetic field component. Usually, DFs are preceded by a small decrease in $B_{Z}$ or even negative $B_{\mathrm{Z}}$. Field dipolarizations/DFs preceded by a small decrease in $B_{\mathrm{Z}}$ simultaneously with earthward convective plasma flow were brought to attention by several authors (Ohtani et al., 1992; Shiokawa et al., 2005). Particularly, Shiokawa et al. (2005) showed rapid decreases in $B_{\mathrm{Z}}$ just before dipolarizations accompanied by electric and magnetic field fluctuations being observed by the Geotail satellite in the near-Earth plasma sheet. Similar results were also reported by Ohtani et al. (1992) based on AMPTE/CCE data. In both studies, reflecting the general conviction, the aforementioned magnetic field features were attributed to an explosive build-up of the cross-tail current prior to its relaxation near substorm onset.
Flux ropes are also magnetic structures commonly observed in the magnetotail. They are characterized by helical magnetic configuration and are formed between multible $\mathrm{X}$ lines. Their most salient feature is the bipolar $B_{\mathrm{Z}}$ signature, coincident with a peak in the $B_{\mathrm{y}}$ component which corresponds to their strong core field. They are most frequently formed in the near-tail region $\left(20-30 R_{\mathrm{E}}\right)$ and their duration measured from the minimum to the maximum of the bipolar $B_{\mathrm{Z}}$ signature ranges from a few tens of seconds to a couple of minutes (Slavin et al., 2003; Ieda et al., 1998). Flux ropes can be observed moving earthward or tailward having a well-defined, quasi-sinusoidal $\mp \delta B_{\mathrm{Z}}$ and $\pm \delta B_{\mathrm{Z}}$ signature, respectively and are generally embedded in a region of high speed flow and plasma beta.

In this paper we report on four substorm events (see Table 1) observed by THEMIS spacecraft on February 2008 during which the five THEMIS were in major conjunction aligned along the Sun-Earth line. To our knowledge, two of them have been studied extensively using in-situ and groundbased measurements to examine timing and causal relationship between substorm features (Angelopoulos et al., 2008, 2009; Lui, 2009; Liu et al., 2009; Zhou et al., 2009a; Pu et al., 2010). All these studies have focused on substorm onset phenomenology trying to resolve whether MR or $\mathrm{CD}$ triggers substorm activity.

In the present work we interpret our observations following a different approach regarding the cause of wave activity and subsequent current disruption/field dipolarization. We support the idea that wave generation is not related to a thinning of the plasma sheet usually attributed to an explosive growth phase, but rather to a merging of vertically oriented, antiparallel magnetic field lines which reconfigures the magnetic field topology from tail-like to dipole-like reducing in this way the cross-tail current.

\section{Instrumentation}

The THEMIS mission was launched on 17 February 2007 and consists of five identical satellites equipped with instrumentation that measures particles and fields (Angelopoulos, 2008). In this paper we use $3 \mathrm{~s}$ time resolution plasma data obtained from the ESA (Electro-Static Analyser) (McFadden et al., 2008) and SST (Solid-State Telescope) (Angelopoulos, 2008) instruments. The THEMIS magnetic field measurements are provided by the FGM (Flux/Gate Magnetometer) instrument (Auster et al., 2008), with time resolution of 3 and $0.25 \mathrm{~s}$, while the electric field data provided by EFI (Electric Field Instrument) (Bonnell et al., 2008) have a time resolution of $0.125 \mathrm{~s}$. In addition, FBK (Filter Bank) data (Cully et al., 2008) are used, which come originally from EFI and SCM (Search Coil Magnetometer) (Roux et al., 2008) instruments. The filter bank data is created by the THEMIS DFB (Digital Fields Board) which performs the spectral processing for the EFI and the SCM. The FBK data are calculated as 
the mean of the absolute value of the bandpass-filtered electric and magnetic field signals, and are therefore in units of amplitude.

\section{Observations}

\subsection{February 2008 substorm event}

On 26 February 2008 the five THEMIS were in a major conjunction, aligned along the Sun-Earth line, with spacecraft P3 located at $\sim 0.2 R_{\mathrm{E}}$ from the nominal neutral sheet (Angelopoulos et al., 2008). The average P3 location, for the time interval 04:50-05:05 UT (Fig. 1), was [-10.9, 3.7, $-2] R_{\mathrm{E}}$, in GSM coordinates. Angelopoulos et al. (2008, 2009) have inferred that onset of tail reconnection occurred at 04:50:03 at $20 R_{\mathrm{E}}$ between $\mathrm{P} 1$ and P2 further tailward of P3 although this has been an issue under debate (Lui, 2009). Based on auroral signatures they have defined 04:52:21 UT as the time of the substorm expansion onset.

Figure 2 gives an overview of electric and magnetic wave measurements along with the $B_{\mathrm{x}}, B_{\mathrm{y}}$, and $B_{\mathrm{z}}$ magnetic field components in GSM coordinates, the calculated $V_{\mathrm{X}}$ convective plasma velocity also in GSM coordinates, the magnetic field intensity and the ion density. The first and second panels show the electric and magnetic pseudo-power spectra which were obtained from EFI signals (sensors $1 \& 2$ in the spin plane) from opposing sides of the spacecraft and SCM signals from one of the three magnetic field axes, respectively. The main feature here is a broadband electromagnetic emission at low frequencies starting at $\sim 04: 53$ UT. Based on panels (c) and (e), this intense wave initiation is accompanied by a simultaneous moderate decrease in $B_{\mathrm{Z}}$ magnetic field component (from $5 \mathrm{nT}$ to $3 \mathrm{nT}$ ) followed by a prominent field dipolarization starting at $\sim 04: 53: 05$ UT with $B_{\mathrm{Z}}$ component reaching values up to $17 \mathrm{nT}$, while $B_{\mathrm{X}}$ shows a sharp dipping towards zero which lasts for a few seconds. Coincident with the $B_{\mathrm{x}}$ dipping is an enhancement in $B_{\mathrm{y}}$ reaching values up to $-8 \mathrm{nT}$. The wave activity enhancement extents from below the lower hybrid frequency $\left(f_{\text {ih }}\right)$ (ranging between 10 and $50 \mathrm{~Hz}$ ) up to $500 \mathrm{~Hz}$ (near the electron cyclotron frequency). The magnetic field just before the wave activity initiation was relatively stretched with the earthward convective plasma velocity being almost zero (panel f). One distinct feature in the profiles (vertical colored bar) is that waves start to appear by the time the earthward convective flow velocity has reached a value of $\sim 150 \mathrm{~km} \mathrm{~s}^{-1}$ and $B_{\mathrm{Z}}$ has started to decrease. Magnetic field intensity in panel $(\mathrm{g})$ shows clear compression in coincidence with field dipolarization. An interesting observational feature is the narrow spike in plasma density shown in panel (h) which implies compression of the plasma population due to the earthward convective plasma flow.

After the first prominent field dipolarization at $\sim 04: 53: 10$ UT there is a time interval of $\sim 8.5 \mathrm{~min}$ characterized by intense wave activity which is accompanied
Table 1. Four THEMIS dipolarization events that have been investigated and which show similar features. From all four events, only the 3 rd one does not show a clear $(-/+) B_{\mathrm{Z}}$ polarity reversal.

\begin{tabular}{lccc}
\hline Date & Event time & Probe & $\begin{array}{c}\text { Clear } B_{\mathrm{Z}} \\
\text { reversal }\end{array}$ \\
\hline 26 Feb 2008 & $\sim 04: 53 \mathrm{UT}$ & P3 & Yes \\
22 Feb 2008 & $\sim 04: 37 \mathrm{UT}$ & P3 & Yes \\
22 Feb 2008 & $\sim 06: 26 \mathrm{UT}$ & P3 & No \\
14 Feb 2008 & $\sim 02: 44 \mathrm{UT}$ & P3 & Yes \\
\hline
\end{tabular}

by a magnetic field being turbulent and often reversing its radial direction. The earthward convective plasma flow consists mainly of three prominent velocity pulses which appear during the time intervals 04:53:00-04:54:10 UT, 04:54:30-04:55:30 UT, and 04:58:00-05:00:00 UT, respectively. During these three intervals the field exhibits clear dipolarization signatures with wave activity being very intense. After $\sim 05: 01: 30$ UT what is observed, is a general stabilization of all parameters. There is a plasma flow and a wave activity cessation, both having very low values compared to previous levels. Plasma sheet enhanced $B_{\mathrm{Z}}$ fluctuations before that time now start to cease with magnetic field obtaining a relatively stable dipolarized configuration (panel e).

\subsection{February 2008 substorm events}

A substorm event occurred at $\sim 04: 36$ on 22 February 2008, while all five THEMIS spacecraft were aligned along the Earth's magnetotail in a major conjunction with P3 deep inside the plasma sheet, very close to the neutral sheet (Liu et al., 2009). Based on observations from THEMIS P1 and P2 which were then inside the plasma sheet but close to its southern edge, Liu et al. (2009) concluded that tail reconnection occurred between 04:34:25 UT and 04:35:04 between $\sim 19.5$ and $\sim 22.4 R_{\mathrm{E}}$ downtail. The reconnection location was between the P1 and P2 spacecraft. The reconnection onset time was determined to be about 2 min earlier than the high-latitude Pi2 onset at $\sim 04: 36: 43$ UT and the auroral intensification onset at $\sim 04: 36: 55$ UT. During this time interval, the average location of $\mathrm{P} 3$ was $[-10.9,2.2,-3.4] R_{\mathrm{E}}$ in GSM coordinates.

The same parameters as in Fig. 2 are presented for P3 in Fig. 3 during the period 04:32-04:47 UT on 22 February 2008. At $\sim 04: 36: 49$ UT intense wave activity in the electric and magnetic field data starts to be observed. This is associated with an abrupt decrease in the $B_{\mathrm{Z}}$ component of the magnetic field, which reaches zero values and subsequently changes polarity. This $B_{\mathrm{Z}}$ reversal occurs prior to the field dipolarization which starts at $\sim 04: 36: 55 \mathrm{UT}$, with the $B_{\mathrm{Z}}$ component reaching values up to $10 \mathrm{nT}$. As shown in Fig. 3, the abrupt decrease in $B_{\mathrm{Z}}$ coincident with the 


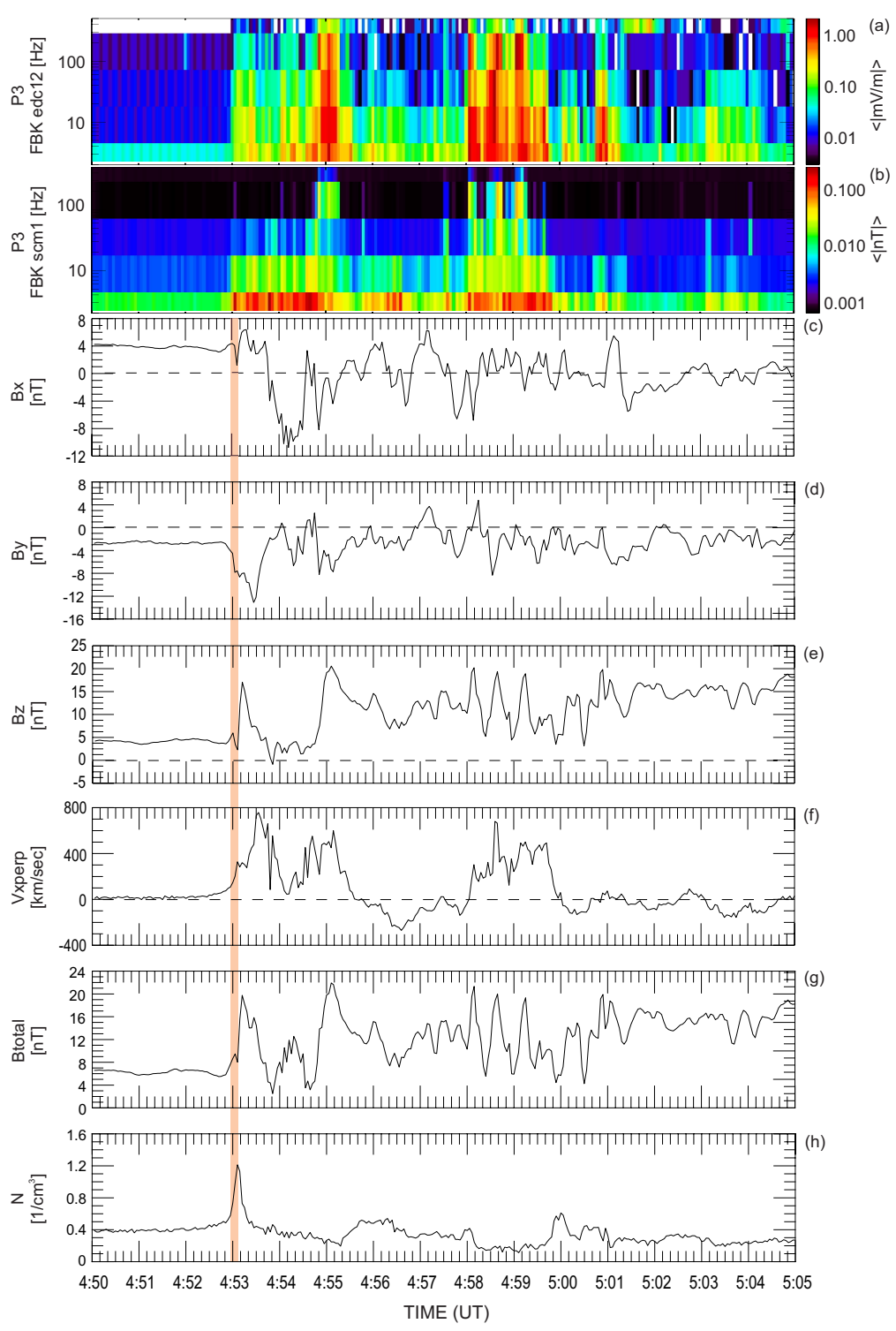

Fig. 2. An overview of wave power, magnetic field and plasma moments measurements from P3 spacecraft between 04:50-05:05 UT on 26 February 2008. The first two panels are the on-board computed wave pseudo-power (mean amplitude) spectra obtained from the EFI and SCM instruments consisted of filter bank spectral bands covering the range from $\sim 2 \mathrm{~Hz}$ to $\sim 500 \mathrm{~Hz}$. Magnetic field components $B_{\mathrm{X}}, B_{\mathrm{y}}$, and $B_{\mathrm{Z}}$ from FGM instrument are plotted in panels (c), (d), and (e). Panel (f) presents the calculated earthward convective plasma flow derived from ESA measurements. Magnetic field intensity is plotted in panel (g). Plasma density is shown in panel (h).

initiation of wave activity is well-correlated with the observation of convective plasma flow velocity, which has a value of $\sim 100 \mathrm{~km} \mathrm{~s}^{-1}$. This fast plasma flow according to Liu et al. (2009) is interpreted as due to reconnection-related compression of the plasma earthward of the reconnection site and cannot be attributed to local effects in the central plasma sheet. P4 was very close to P3 observing similar features as $\mathrm{P}$, regarding wave activity, earthward convective plasma flow and magnetic field dipolarization (not shown). The $B_{\mathrm{Z}}$ component in P3 decreased gradually and was further accompanied by a polarity reversal, while the embedded magnetic structure inside the earthward propagating BBF exhibited an enhanced $B_{\mathrm{y}}$ core just prior to dipolarization onset.

One major observational feature similar to Fig. 2 is the very good correlation between plasma wave activity and earthward convective flows. While $B_{\mathrm{x}}$ magnetic field component is fluctuating around zero implying that THEMIS satellites are repeatedly traversing the current sheet, $B_{\mathrm{Z}}$ is intensively fluctuating having most of the time a dipolarized configuration which at $\sim 04: 41$ UT starts to demonstrate a more stable dipolarized behavior. This dipolar stabilization of the magnetic field is very well correlated with plasma flow 


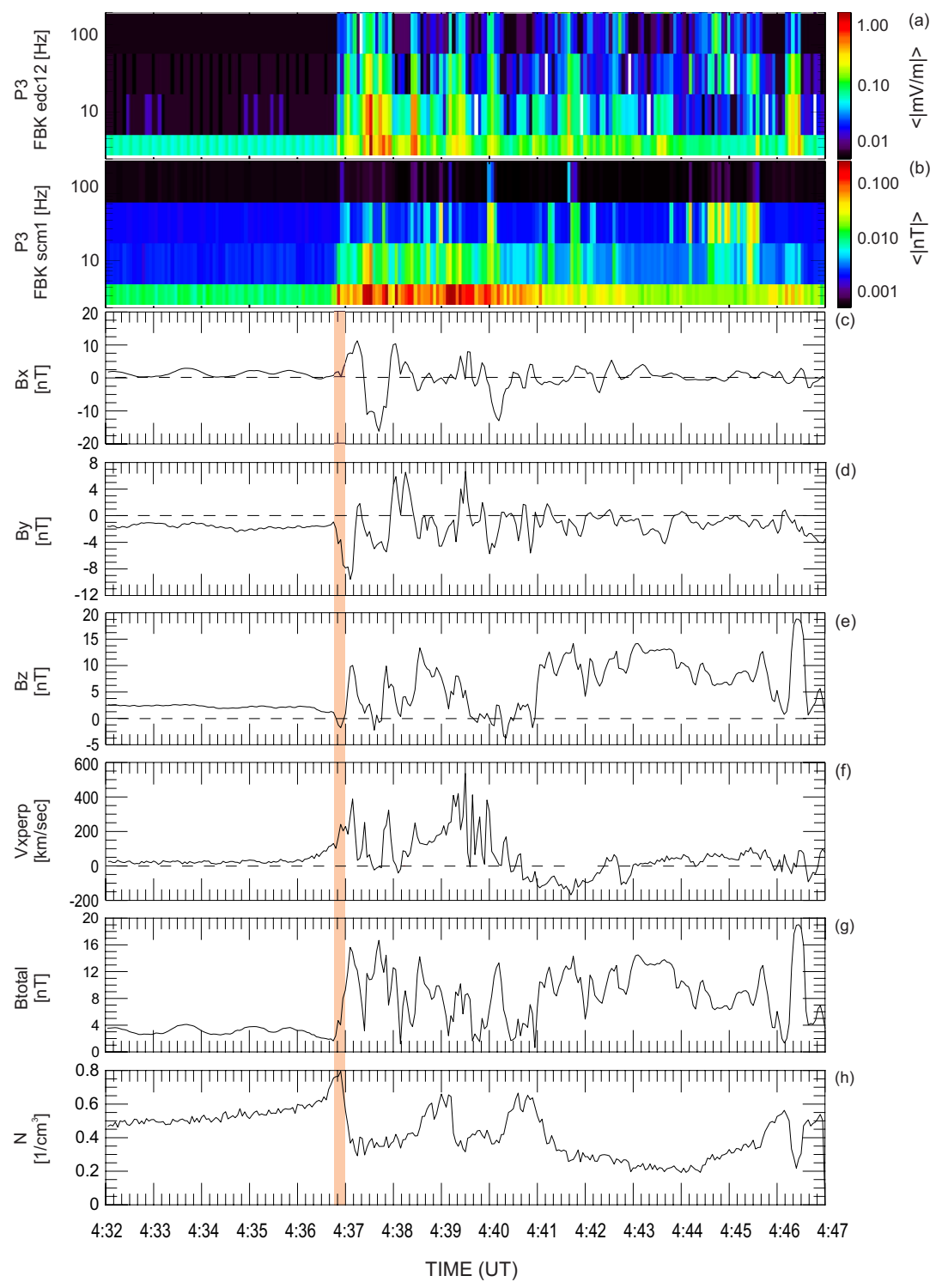

Fig. 3. Same format as Fig. 2 but for a 22 February 2008 substorm event. The measurements are from P3 spacecraft for the time interval 04:32-04:47 UT and the spectral bands cover the frequency range from $\sim 2 \mathrm{~Hz}$ to $\sim 300 \mathrm{~Hz}$.

cessation deep inside the central plasma sheet with $B_{\mathrm{X}}$ being almost zero and plasma wave activity having very low levels.

The observations made by P3 for another relatively small substorm event are presented in Fig. 4 during the period 06:22-06:32 UT, on 22 February 2008 with the same format as Fig. 2. This event occurred $\sim 1.5 \mathrm{~h}$ after the event described above. The THEMIS AE index (not shown) started to increase at $\sim 06: 10 \mathrm{UT}$. At $\sim 06: 20 \mathrm{UT}$, it increased gradually up to $\sim 200 \mathrm{nT}$. At 06:25 UT P3 was at $[-11.3,2.1,-2.7] R_{\mathrm{E}}$ with the spacecraft located at $\sim 0.2 R_{\mathrm{E}}$ south from the nominal neutral sheet. As shown in panel (e) in Fig. 4 (vertical colored bar) there was a decrease in $B_{\mathrm{Z}}$ component appearing while the plasma flow reached its nearly maximum value $\left(\sim 250 \mathrm{~km} \mathrm{~s}^{-1}\right)$ and was characterized by a broad emission both in electric and magnetic field. Strong dipolarization and compression of the magnetic field preceded by plasma sheet compression were observed with $B_{\mathrm{Z}}$ and $B_{\text {total }}$ reaching values up to $20 \mathrm{nT}$ and $22 \mathrm{nT}$, respectively. P4 observed similar features as P3 with even more pronounced decrease in $B_{\mathrm{Z}}$ which exhibited a two-step structure (not shown).

\subsection{February 2008 substorm event}

In Fig. 5 observations obtained by P3 are presented for the time interval 02:40-02:55 UT on 14 February 2008, during a small substorm event (THEMIS AE index reached $\sim 200 \mathrm{nT}$ at $\sim 02: 55$ UT) which demonstrates similar features as the previous events. At 02:44 UT, P3 was located at $[-10,3.4$, 


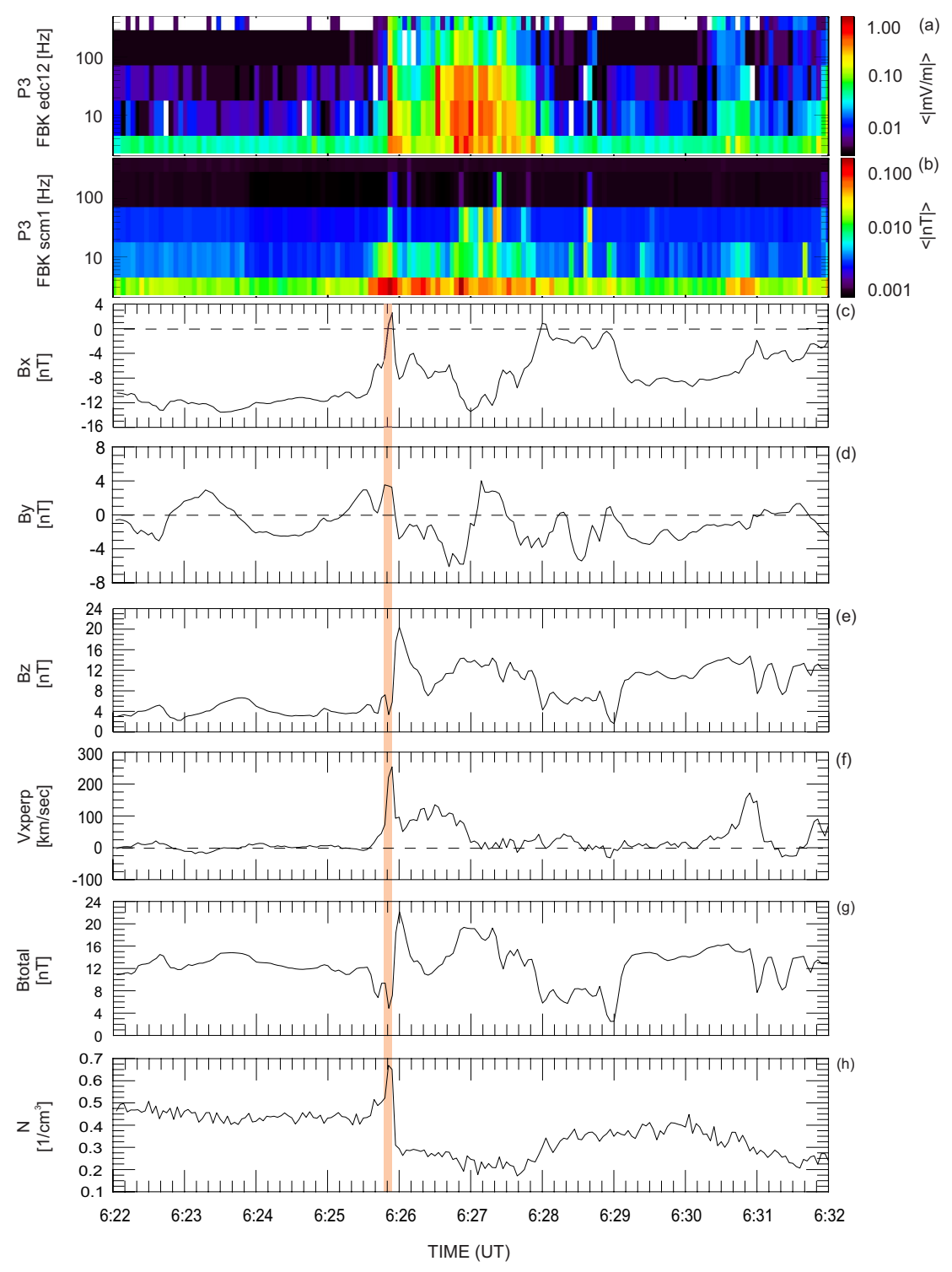

Fig. 4. Same format as Fig. 2 but for a 22 February 2008 substorm event. The measurements are from P3 spacecraft for the time interval 06:22-06:32 UT and the spectral bands cover the frequency range from $\sim 2 \mathrm{~Hz}$ to $\sim 500 \mathrm{~Hz}$.

$-2.2] R_{\mathrm{E}}$, very close to the neutral sheet. A noteworthy feature is the steep decrease in $B_{\mathrm{Z}}$ from $\sim 10 \mathrm{nT}$ to near zero in a very short time accompanied by a $B_{\mathrm{x}}$ reduction, as well. Immediately afterwards a dipolarization is observed which reaches a value up to $25 \mathrm{nT}$. After this prominent field dipolarization P3 observes $B_{\mathrm{Z}}$ to be turbulent for a relatively long time ( $\sim 4 \mathrm{~min})$ and then relaxing to a more stable dipolarized configuration at $\sim 02: 49$ UT. While magnetic field intensity demonstrates similar behavior as in the other events that is, very low values just before field dipolarization implying that we are very close to the current sheet and then sharp enhancement coincided with field dipolarization, plasma density does not show any peak before dipolarization with its value being at the same level with that of the preexisting plasma population.

\subsection{Zoomed-in plots}

In order to elaborate further the four dipolarization events already presented, we show in Fig. 6 four zoomed-in plots (a)(d) (hereinafter referred to as events 1, 2, 3, and 4) of 34 min time duration each around the time of dipolarization. Each plot consists of five panels showing magnetic field intensity, $B_{\mathrm{y}}$ and $B_{\mathrm{z}}$ magnetic field components in GSM coordinates both with $0.25 \mathrm{~s}$ time resolution, and energetic ion and electron differential energy fluxes versus azimuthal angle in the probe spin plane, as measured by the SST instrument in the $30-300 \mathrm{keV}$ energy range. As it is evident from the $B_{\mathrm{Z}}$ panels, $B_{\mathrm{Z}}$ shows clear dipolarizations as it was expected, however, because of using higher time resolution, features of negative polarity change are clearly revealed. The negative 


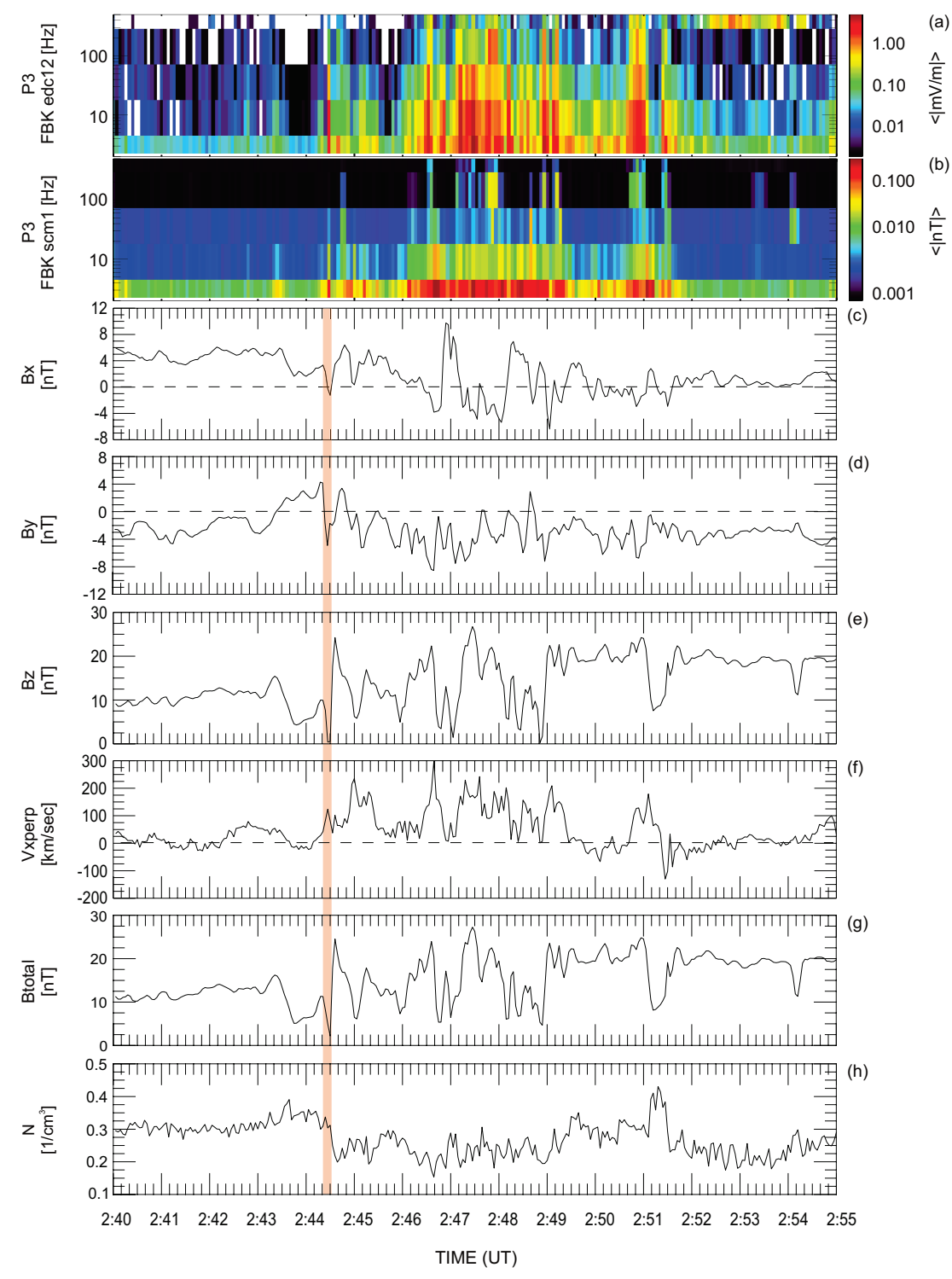

Fig. 5. Same format as Fig. 2 but for a 14 February 2008 substorm event. The measurements are from $\mathrm{P} 3$ spacecraft for the time interval 02:40-02:55 UT and the spectral bands cover the frequency range from $\sim 2 \mathrm{~Hz}$ to $\sim 500 \mathrm{~Hz}$.

polarity change is clearly seen in events 1,2 , and 4 where values around $-5 \mathrm{nT}$ are attained. In event 3 although $B_{\mathrm{Z}}$ is decreasing towards zero obtaining even negative values, one could not argue that there is a clear $B_{\mathrm{Z}}$ polarity reversal.

For all four events observed by P3, plasma sheet populations were exhibiting a clear steady azimuthal anisotropy peaking at $\sim+70^{\circ}$ suggesting that more ions were moving in the earthward and duskward direction. This anisotropy was more pronounced in event 1 and even more in event 2 where P3 was continuously at the neutral sheet based on the magnetic field magnitude being less than $4 \mathrm{nT}$ and $B_{\mathrm{x}}$ being around zero (Fig. $3 \mathrm{c}$ and $3 \mathrm{~g}$ ). A few seconds before and during $B_{\mathrm{Z}}$ negative reversals, energetic ions superimposed over the preexisting plasma sheet populations gradually appeared having flow patterns in the opposite sense, that is, streaming earthward and dawnward at $\sim-70^{\circ}$. These flow patterns were gradually becoming more earthward while approaching the magnetic structures $\left(+/-B_{\mathrm{Z}}\right.$ reversals). What is shown in $B_{\text {total }}$ panels is that the intense appearance of the energetic ions coincided with a gradual increase in the magnetic field intensity. This in turn implies that these ion populations made their prominent appearance at P3 while the magnetic field was compressed just before the arrival of the magnetic structures at P3 (vertical dashed lines) similarly to the earthward flowing plasmoid reported by Zong et al. (2004). In contrary to the energetic ions behavior, energetic electron populations show clear depletions in all azimuthal directions right at the time of negative $B_{\mathrm{Z}}$ reversals, that is, 

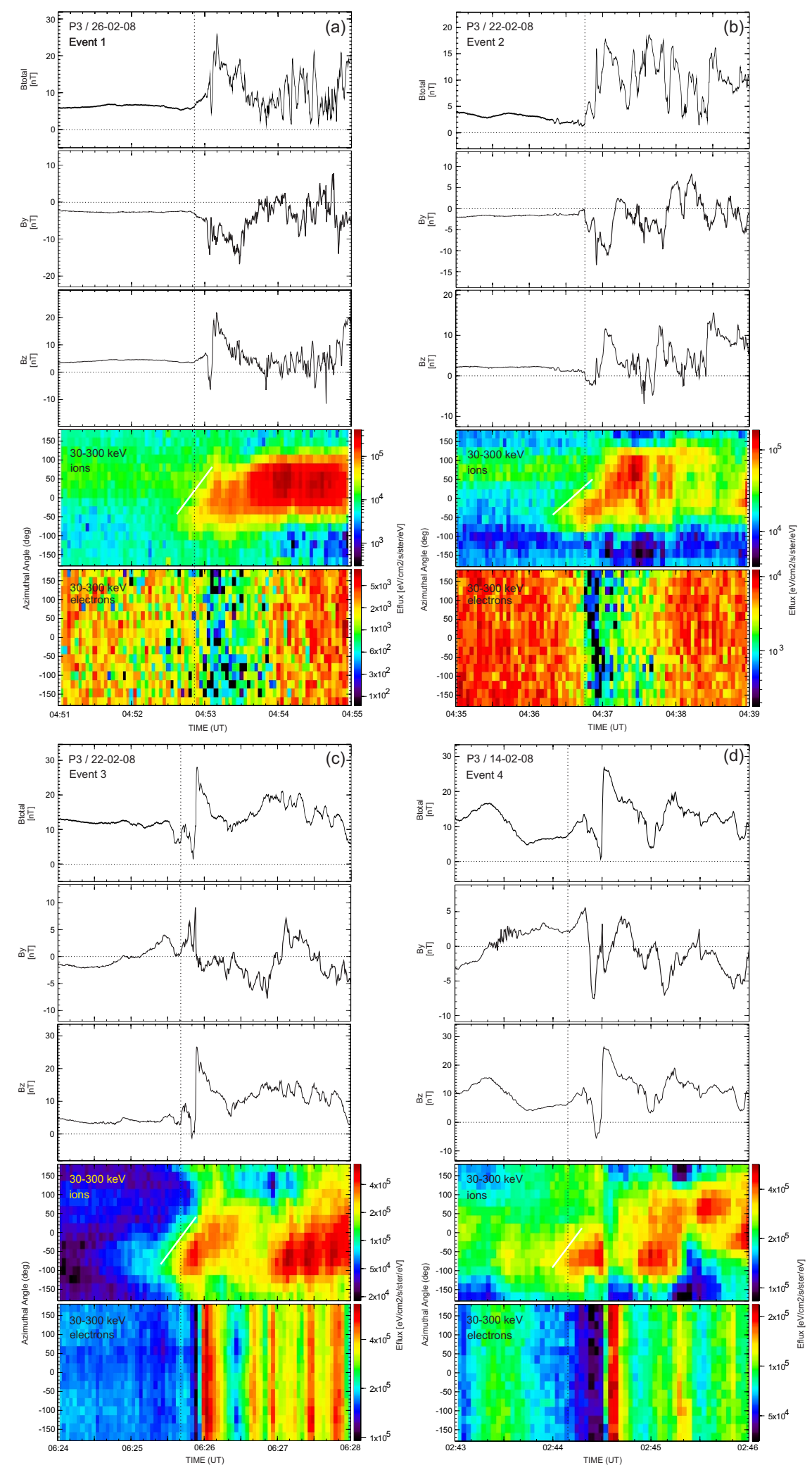

Fig. 6. Time-zoomed plots of all four individual dipolarization front events. Each plot consists of five panels. Magnetic field intensity, $B_{\mathrm{y}}$, and $B_{\mathrm{Z}}$ magnetic field components in GSM coordinates are plotted in the first three panels of each plot with a $0.25 \mathrm{~s}$ time resolution. The fourth and fifth panels of each plot present ion and electron differential energy fluxes versus azimuthal angle in the probe rotation plane, measured by the SST instrument in the $30-300 \mathrm{keV}$ energy range. Zero degrees correspond to earthward fluxes. Note that in $B_{\text {total }}$ panels zero level is shifted for clarity. 

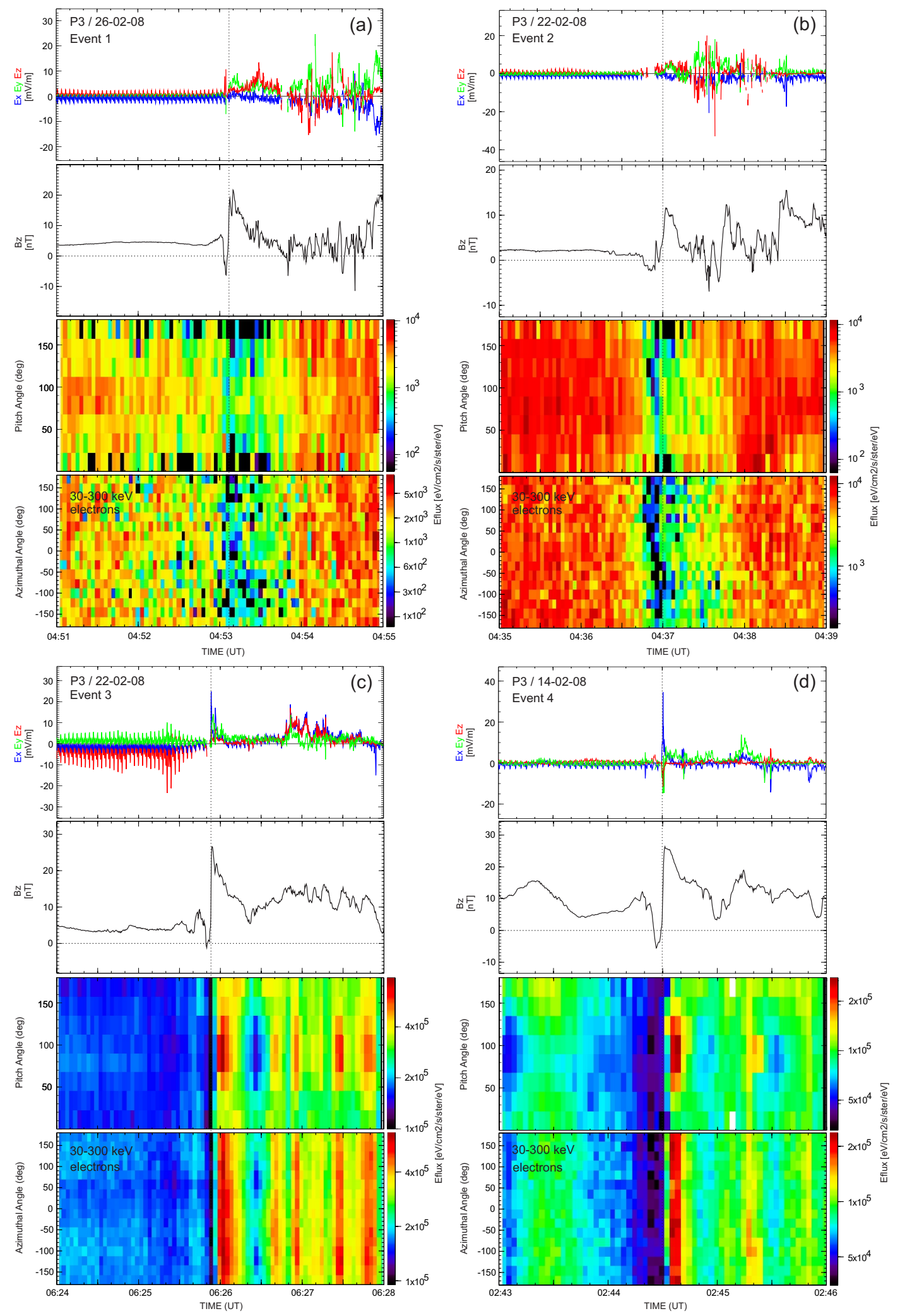

Fig. 7. Time-zoomed plots of all four individual dipolarization front events for energetic electrons only. Each plot consists of four panels. Electric field components and $B_{\mathrm{Z}}$ magnetic field component in GSM coordinates are plotted in the first two panels of each plot with a 0.125 and $0.25 \mathrm{~s}$ time resolution, respectively. The third and fourth panels of each plot present electron differential energy fluxes versus pitch and azimuthal angle, respectively, measured by the SST instrument in the 30-300 keV energy range. The vertical dashed lines denote the inductive electric fields associated with the dipolarized flux tubes/dipolarization fronts. 
when the magnetic structures encounter P3 satellite indicating that the energetic particle composition at the magnetic structures' core is significantly different compared to the ambient plasma.

In Fig. 7, as in Fig. 6, we show time-zoomed plots but now we concentrate only on energetic electrons in order to infer conclusions regarding the nature of electron energization during dipolarization fronts. What is shown from top to bottom in plots (a)-(d) are the electric field components in GSM coordinates $\left(0.125 \mathrm{~s}\right.$ resolution), $B_{\mathrm{z}}$, and differential energy fluxes versus pitch and azimuthal angle. The most important feature in these plots, by comparing events 1,2 with 3,4 is the different electron response to dipolarization fronts. While in events 1 and 2, there is an electron depletion both in pitch and azimuthal angles, in events 3 and 4 electrons right after the dipolarization fronts are well modulated demonstrating fine pitch angle anisotropies peaked at 90 degrees evident in all azimuthal angles. All the events are accompanied by transient, short-lived electric fields although their magnitudes in events 1 and 2 are limited only up to $6-7 \mathrm{mV} \mathrm{m}^{-1}$, in antithesis to events 3 and 4 where electric fields exceed $20 \mathrm{mV} \mathrm{m}^{-1}$ reaching values up to $30 \mathrm{mV} \mathrm{m}^{-1}$, similar to the intense electric fields reported by Sergeev et al. (2009) and Deng et al. (2010).

\section{Interpretation and discussion}

The observations already presented strongly suggest that the magnetic disturbances propagating earthward are actually flux ropes structures embedded in fast plasma sheet flows following the onset of BBFs. Our conclusion is strongly supported by previous studies (e.g. Imber et al., 2011, Fig. 3 (left)) where an earthward traveling flux rope observed by THEMIS P2 at $X=-16 R_{\mathrm{E}}$ demonstrates pretty much the same magnetic field and plasma flow signatures as those shown in our events. The flux ropes are accompanied by energetic ions which are meandering dawnward opposite to the preexisting plasma sheet population. This ion motion earthward and dawnward could be understood in terms of Speiser-type trajectories (Speiser, 1965; Büchner and Zelenyi, 1989; Speiser, 1991) where ions originally executing meandering orbits across the current sheet would be eventually ejected from it toward the Earth in the presence of a small southward magnetic field combined with a dawnward electric field. The injected fresh energetic ion population earthward and dawnward in front of the flux ropes will be superposed with the preexisting duskward streaming ambient ions that carry the cross-tail current forming an "azimuthally bi-directional" pattern. As the flux ropes are approaching P3, the earthward-dawnward flow patterns start to diminish into more earthward ones implying that ions are observed right at the time of their generation meaning that they have not been injected upstream of the flux ropes yet (white oblique lines in Fig. 6).
Previous simulation studies (Zhou et al., 2010, 2011) have successfully reproduced ion flow patterns similar to those shown in the present study. Particularly, Zhou et al. (2010) based on test-particle simulations suggested a mechanism of energetic (30-45 keV) ion pickup acceleration by showing that the observed ion evolution was consistent with a picture of ions reflected and accelerated by the approaching dipolarization front and moving ahead of it. In their simulation model the evolution of the ion distributions was constructed by adopting a northward $B_{\mathrm{Z}}$ to model the earthward propagation of the dipolarization front combined with a dawndusk electric field. Their model was able to reproduce well the main observational features of ion flows showing that ions were executing cucumber-type trajectories. However, according to the observational data in the present study one should also consider the case where ions interact with a negative $B_{\mathrm{Z}}$ in the presence of a dawnward electric field although such a modeling effort is hard to be implemented in a selfconsistent manner.

As already mentioned, the observational features presented in this paper support the idea that we are indeed dealing with flux ropes immersed in the central plasma sheet closely associated with the onset of bursty bulk flow events with a peak speed above $\sim 250 \mathrm{~km} \mathrm{~s}^{-1}$ (e.g. Moldwin and Hughes, 1994; Slavin et al., 2003) except for the last BBF in Fig. 5 which had a peak velocity $\sim 100 \mathrm{~km} \mathrm{~s}^{-1}$. However, one could point out the discrepancy observed in $B_{\mathrm{Z}}$ profiles where there is a profound asymmetry between southward and northward $B_{\mathrm{Z}}$ perturbations. In three of the events presented, although $B_{\mathrm{Z}}$ reaches negative values its positive perturbations have greater absolute values than the corresponding negative ones. Only in the event shown in Fig. 6c $B_{Z}$ does not demonstrate a clear bipolar signature. This particular $B_{\mathrm{Z}}$ signature could be explained in terms of the coordinate system being used. Generally, bipolar signatures observed in the GSM coordinate system need not pass through zero level to represent a flux rope due to the fact that flux ropes are not necessarily perfectly oriented with GSM axes (e.g. Walsh et al., 2007). Furthermore, the $B_{\mathrm{y}}$ magnetic signatures observed in all the events are consistent with the interpretation of earthward propagating magnetic flux ropes having an enhanced core magnetic field both in $+\mathrm{y}$ - and $-\mathrm{y}$-directions whose direction is modulated by the IMF $B_{\mathrm{y}}$ polarity (Hughes and Sibeck, 1987; Moldwin and Hughes, 1991; Slavin et al., 2003). The fact that in all dipolarization events the positive $B_{\mathrm{Z}}$ enhancements show much larger values can be explained in terms of magnetic field compression being much more pronounced at the trailing edge of the flux ropes due to the high-speed earthward convective flows (see Fig. 8 for a schematic explanation).

For the generation of the earthward flux rope events showed in this paper we adopt the interpretation presented by Slavin et al. (2003) who after examining similar events and using the term BBF-type flux ropes proposed that their formation mechanism can be easily understood in terms of 


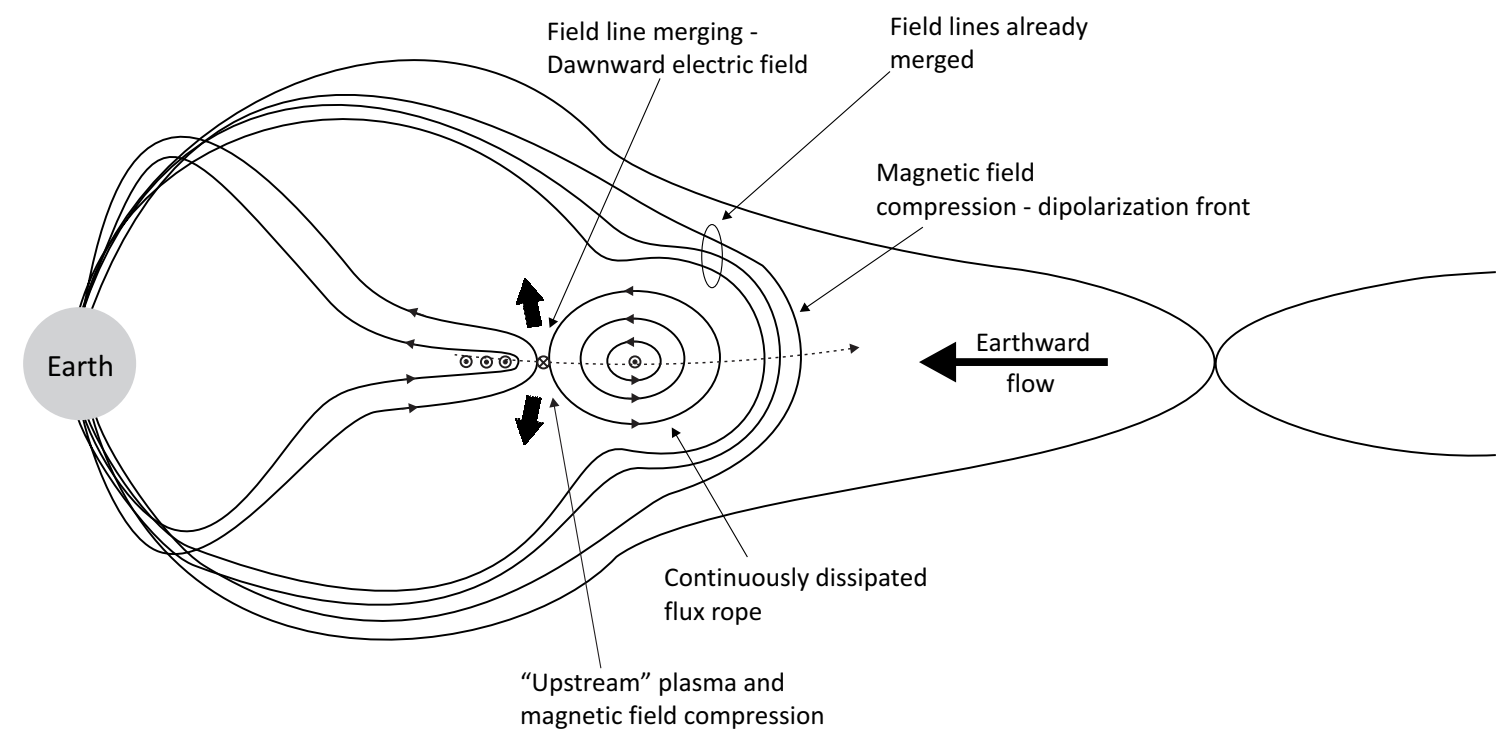

Fig. 8. A qualitative schematic diagram in $X Z$ plane depicting our conceptual context according to our observations. The flux rope structures are formed due to multiple reconnection X-lines (MRX) in the near-tail, an idea first introduced by Slavin et al. (2003). The flux ropes are then being "trapped" inside closed magnetic field lines and accelerated earthward, presumably as a result of a combination of magnetic tension forces and plasma convection. Existence of a sequence of flux ropes propagating earthward is the likely case. Their dissipation would eventually result in multiple substorm onsets all contributing to the same major substorm phenomenon and final relaxation of the magnetotail into a dipolar configuration. Cross-tail current is disrupted by the magnetic field reconfiguration due to field line merging. Thick black arrows denote the presumed plasma outflow regions. Dashed arrow denotes the THEMIS spacecraft relative trajectory.

multiple reconnection X-lines (MRX) formation in the neartail. Based on this mechanism, the simultaneous reconnection of tail field lines at $N+1 \mathrm{X}$-lines leads to the generation of $N$ flux ropes. This idea has also been supported by Zong et al. (2004) where their observations clearly revealed earthward moving plasmoid structures.

All the dipolarization events in this study were associated with earthward bursty bulk flows with velocities ranging from $\sim 100 \mathrm{~km} \mathrm{~s}^{-1}$ to $\sim 750 \mathrm{~km} \mathrm{~s}^{-1}$ (Angelopoulos et al., 1992; Cao et al., 2006). In all the cases identified the flux ropes were observed near the leading edge of the earthward flow events. If the flux ropes were pushing up against oppositely directed terrestrial closed magnetic field lines sweeping the undisturbed "upstream" plasma sheet there would be an intense variation in plasma population identified by a peak in plasma density indicating a build-up of plasma pressure on the earthward side of the flux ropes. This effect along with the build-up of magnetic field pressure is what we are indeed observing (vertical dashed lines in Fig. 6).

Dipolarization fronts embedded in fast earthward bursty bulk flows generated by near-Earth reconnection soon encounter the strong dipolar field of the inner magnetosphere having as a result the enhancement/pileup of the northward magnetic flux of the background dipole magnetic field. The ensuing tailward pressure force at the transition region between dipolar and tail-like magnetic field configurations has the effect of decelerating the earthward flows. This flow braking is accompanied by the generation of a dawnward cross-tail current at the stopping point. The above substorm scenario is the result of a synthesis of previous studies (Haerendel, 1992; Shiokawa et al., 1997, 1998; Baumjohann et al., 1999). Under our interpretation context this dawnward inertia current can be thought of as the dawnward current sheet generated by the merging of the oppositely directed, vertically oriented field lines of the near-Earth stretched magnetotail and the flux rope front side, with the outer layers of the flux rope being essentially stripped away as it travels further earthward. In fact, such observational evidence has been already reported by Henderson et al. (2006) in a study examining flux rope structures in the near-tail based on Cluster data. After applying the curlometer technique, they noticed the existence of a large enhancement of current just before the flux rope core along the flux rope's axial direction, but directed oppositely to the current inside the flux rope. If viewed globally, this effect can be understood as a propagating current sheet oriented in the west to east direction.

In our conceptual framework, the resulting magnetic field reconfiguration into a dipolar geometry is the cause of the cross-tail current disruption and current wedge formation. Furthermore, the dipolarization fronts being observed are nothing else but compressed dipolarized flux tubes originating from the merging of the outer layers of the flux ropes, that is to say, the compressed trailing edges of the "degenerated" flux ropes embedded inside the BBFs. Similar observational features have been justified in terms of plasma bubbles (Runov et al., 2009), although such an interpretation cannot 
explain the typical signature of dipolarization fronts, that is, the negative dip preceding the sharp increase in $B_{\mathrm{z}}$. In contrary, this typical feature is accepted as a "de facto" signature without going into further substantiation.

Previous studies analyzing dipolarization events have reported characteristic waves having frequencies of $5-20 \mathrm{~Hz}$ which are in the range of the lower hybrid waves (Shiokawa et al., 2005; Zhou et al., 2009b) and electromagnetic waves in the whistler frequency range between local ion and electron cyclotron frequency (Contel et al., 2009). These kinds of wave modes are typically found near reconnection sites where sufficiently thin current sheets are generated (Vaivads et al., 2006, and references therein). Thus, based on our conceptual framework it seems that the observed wave modes during the dipolarization events do not owe their existence to current sheet thinning but to field line merging which is much identical to midtail magnetic reconnection. Previous studies examining dipolarization events and the associated current disruption have treated plasma waves as being the cause of the magnetic reconfiguration from tail-like to dipole-like (Lui et al., 1990, 1991, 1992; Lui, 2004). According to our notion, we adopt the opposite idea that the observed wave activity is the effect and not the cause triggered by antiparallel magnetic field merging.

The flux ropes seem to act in the opposite sense for energetic ions and electrons when they encounter THEMIS probe. From one hand, energetic ion's energization seems to be a continuous process taking place in front of the flux ropes starting a few seconds before the $B_{\mathrm{Z}}$ negative reversals with the ion population "being carried" earthward by the magnetic structure. On the other hand, in the case of energetic electrons, the flux ropes seem to carry earthward an electron population that is subjected to depletion. This could be explained based on the fact that energetic electrons (e.g. $50 \mathrm{keV}$ ) travel along field lines with a high speed of around $20 R_{\mathrm{E}} \mathrm{S}^{-1}$. These swift electrons trace out field lines in the magnetosphere in a few seconds, therefore, can provide nearly instantaneous information about the magnetic field configuration in the geospace regions. Hence, the lack of energetic electrons inside the flux ropes suggests that these entities have started to act as open field line structures way before we observe them. On the other hand, the fact that electrons after magnetic field dipolarizations are observed in all azimuthal directions only in events 3 and 4 where electric fields are much higher than those in events 1 and 2, implies the local/temporal nature of the acceleration mechanism. Hence, the observations in Fig. $7 \mathrm{c}$ and $7 \mathrm{~d}$ seem to indicate that, (a) electrons are locally accelerated by the intense transient in nature electric fields $\left(>20 \mathrm{mV} \mathrm{m}^{-1}\right)$ associated with field dipolarizations and (b) electrons conserve their first adiabatic invariant in the enhanced dipolarized field which results in the peaked at 90 degrees pitch angle distributions. Such electric field features are characteristic of nonlinear electrostatic structures such as electrostatic solitary waves and double layers (Deng et al., 2010). As suggested by Deng et al. (2010), these nonlinear electrostatic structures can interact with electrons and generate the observed perpendicular high energy electron distributions.

In Fig. 8 we present schematically the main phenomena taking place during the substorm events. Our scenario explains in a satisfactory way the intensive wave activity lasting for several minutes and occurring simultaneously with successive field dipolarizations. These active periods in all the events can be understood in terms of multiple earthward propagating flux ropes being continuously dissipated while convected towards the Earth. Thus, wave activity cessation coincides with the time at which the last flux rope structure passes over THEMIS spacecraft and magnetotail relaxes in its final dipolar configuration. Furthermore, between two successive flux rope passages, one would expect the magnetotail to stretch again in a tail-like configuration due to plasma convection associated with an enhanced solar wind electric field.

\section{Synopsis}

In this paper we have investigated four substorm events captured by P3 THEMIS spacecraft in February 2008. For our analysis we used wave, plasma, electric and magnetic field data. All the substorm events exhibited several common features: (1) all of them were detected when THEMIS spacecraft was in the central plasma sheet near the neutral sheet; (2) strong earthward convective plasma flows accompanied by intense low-frequency electric and magnetic wave activity; (3) $B_{\mathrm{Z}}$ magnetic field component polarity change just prior to magnetic field dipolarization signalling wave activity initiation; (4) plasma and magnetic field compression prior to and during field dipolarization, respectively. Based on these common observational characteristics we have interpreted the initial earthward propagating disturbances as being flux ropes embedded inside fast earthward convective plasma flows in the inner central plasma sheet. We made an attempt to shed light on aspects pertaining to the mechanism which is responsible for the reduction of the crosstail current, the ensuing field dipolarization and the associated particle energization. In contrast to the "classic" view of cross-tail current disruption due to plasma sheet thinning and the excited wave turbulence we have adopted an alternative scenario for substorm onset and expansion which is based on merging with the background geomagnetic field and the eventual dissipation of earthward propagating flux ropes. Finally, the development of self-consistent model of test-particle simulations under our conceptual framework that could reproduce the presented observational data is a key element in strengthening our ideas. Despite the difficulties that such a modeling effort could have, such simulations could reveal the real physical context under which ions are accelerated by the earthward propagating dipolarization fronts. 
Acknowledgements. I. I. Vogiatzis sincerely thanks V. Angelopoulos for use of data from the THEMIS mission and the THEMIS team for doing such a professional job in developing the necessary software for processing and visualizing the data presented in this study. The work was supported by the Hellenic State Scholarships Foundation (IKY), contract 987, National Natural Science Foundation of China (NSFC) grant 41050110440 and Space Research Laboratory at Democritus University of Thrace.

Guest Editor A. Masson thanks I. Dandouras and another anonymous referee for their help in evaluating this paper.

\section{References}

Angelopoulos, V.: The THEMIS mission, Space Sci. Rev., 141, 5-34, 2008.

Angelopoulos, V., Baumjohann, W., Kennel, C. F., Coroniti, F. V., Kivelson, M. G., Pellat, R., Walker, R. J., Lühr, H., and Paschmann, G.: Bursty bulk flows in the inner central plasma sheet, J. Geophys. Res., 97, 4027-4039, 1992.

Angelopoulos, V., Kennel, C. F., Corotini, F. V., Pellat, R., Kivelson, M. G., Walker, R. J., Russell, C. T., Baumjohann, W., Feldman, W. C., and Gosling, J. T.: Statistical characteristics of bursty bulk flow eventes, J. Geophys. Res., 99, 21257-21280, 1994.

Angelopoulos, V., Corotini, F. V., Kennel, C. F., Kivelson, M. G., Walker, R. J., Russell, C. T., McPherron, R. L., Sanchez, E., Meng, C.-I., Baumjohann, W., Reeves, G. D., Belian, R. D., Sato, N., Friis-Christensen, E., Sutcliffe, P. R., Yumoto, K., and Harris, T.: Multipoint analysis of a bursty bulk flow event on April 11, 1985, J. Geophys. Res., 101, 4967-4989, 1996.

Angelopoulos, V., McFadden, J. P., Larson, D., Carlson, C. W., Mende, S. B., Frey, H., Phan, T., Sibeck, D. G., Glassmeier, K.H., Auster, U., Donovan, E., Mann, I. R., Rae, I. J., Russell, C. T., Runov, A., Zhou, X.-Z., and Kepko, L.: Tail reconnection triggering substorm onset, Science, 321, 931-935, 2008.

Angelopoulos, V., McFadden, J. P., Larson, D., Carlson, C. W., Mende, S. B., Frey, H., Phan, T., Sibeck, D. G., Glassmeier, K.H., Auster, U., Donovan, E., Mann, I. R., Rae, I. J., Russell, C. T., Runov, A., Zhou, X.-Z., and Kepko, L.: Response to comment on "Tail reconnection triggering substorm onset", Science, 324, 5933, doi:10.1126/science.1168045, 2009.

Auster, H. U., Glassmeier, K.-H., Magnes, W., Aydogar, O., Baumjohann, W., Constantinescu, D., Fischer, D., Fornaon, K.H., Georgescu, E., Harvey, P., Hillenmaier, O., Kroth, R., Ludlam, M., Narita, Y., Nakamura, R., Okrafka, K., Plaschke, F., Richter, I., Schwarzl, H., Stoll, B., Valavanoglou, A., and Wiedemann, M.: The THEMIS Fluxgate Magnetometer, Space Sci. Rev., 141, 235-264, 2008.

Baker, D. N., Pulkkinen, T. I., Angelopoulos, V., Baumjohann, W., and McPherron, R. L.: Neutral line model of substorms: Past results and present view, J. Geophys. Res., 101, 12975-13010, 1996.

Baumjohann, W., Hesse, M., Kokubun, S., Mukai, T., Nagai, T., and Petrukovich, A. A.: Substorm dipolarization and recovery, J. Geophys. Res., 104, 24995-25000, 1999.

Birn, J., Hesse, M., Haerendel, G., Baumjohann, W., and Shiokawa, K.: Flow braking and the substorm current wedge, J. Geophys. Res., 104, 19895-19903, 1999.
Bonnell, J. W., Mozer, F. S., Delory, G. T., Hull, A. J., Ergun, R. E., Cully, C. M., Angelopoulos, V., and Harvey, P. R.: The Electric Field Instrument (EFI) for THEMIS, Space Sci. Rev., 141, $303-$ 341, 2008.

Büchner, J. and Zelenyi, L.: Regular and chaotic charged particle motion in magnetotaillike field reversals: 1. Basic theory of trapped motion, J. Geophys. Res., 94, 11821-11842, 1989.

Cao, J. B., Ma, Y. D., Parks, G., Reme, H., Dandouras, I., Nakamura, R., Zhang, T. L., Zong, Q., Lucek, E., Carr, C. M., Liu, Z. X., and Zhou, G. C.: Joint observations by Cluster satellites of bursty bulk flows in the magnetotail, J. Geophys. Res., 111, A04206, doi:10.1029/2005JA011322, 2006.

Le Contel, O., Roux, A., Jacquey, C., Robert, P., Berthomier, M., Chust, T., Grison, B., Angelopoulos, V., Sibeck, D., Chaston, C. C., Cully, C. M., Ergun, B., Glassmeier, K.-H., Auster, U., McFadden, J., Carlson, C., Larson, D., Bonnell, J. W., Mende, S., Russell, C. T., Donovan, E., Mann, I., and Singer, H.: Quasi-parallel whistler mode waves observed by THEMIS during near-earth dipolarizations, Ann. Geophys., 27, 2259-2275, doi:10.5194/angeo-27-2259-2009, 2009.

Cully, C. M., Ergun, R. E., Stevens, K., Nammari, A., and Westfall, J.: The THEMIS Digital Fields Board, Space Sci. Rev., 141, 343-355, 2008.

Deng, X., Ashour-Abdalla, M., Zhou, M., Walker, R., El-Alaoui, M., Angelopoulos, V., Ergun, R. E., and Schriver, D.: Wave and particle characteristics of earthward electron injections associated with dipolarization fronts, J. Geophys. Res., 115, A09225, doi:10.1029/2009JA015107, 2010.

Haerendel, G.: Disruption, balloning or auroral avalanche - on the cause of substorms, in: Proc. of the First International Conference on Substorms (ICS-1), pp. 427-420, Eur. Space Agency, Kiruna, Sweden, 1992.

Henderson, P. D., Owen, C. J., Alexeev, I. V., Slavin, J., Fazakerley, A. N., Lucek, E., and Rème, H.: Cluster observations of flux rope structures in the near-tail, Ann. Geophys., 24, 651-666, doi:10.5194/angeo-24-651-2006, 2006.

Hesse, M. and Birn, J.: On dipolarization and its relation to the substorm current wedge, J. Geophys. Res., 96, 19417-19426, 1991.

Hughes, W. J. and Sibeck, D. G.: On the three dimensional structure of plasmoids, Geophys. Res. Lett., 14, 636-639, 1987.

Ieda, A., Machida, S., Mukai, T., Saito, Y., Yamamoto, T., Nishida, A., Terasawa, T., and Kokubun, S.: Statistical analysis of plasmoid evolution with Geotail observations, J. Geophys. Res., 103, 4453-4465, 1998.

Imber, S. M., Slavin, J. A., Auster, H. U., and Angelopoulos, V.: A THEMIS survey of flux ropes and traveling compression regions: Location of the near-Earth reconnection site during solar minimum, J. Geophys. Res., 116, A02201, doi:10.1029/2010JA016026, 2011.

Liu, J., Angelopoulos, V., Frey, H., McFadden, J., Larson, D., Glassmeier, K., Mende, S., Russell, C. T., Rae, I. J., Murphy, K. R., and Apatenkov, S.: THEMIS observation of a substorm event on 04:35, 22 February 2008, Ann. Geophys., 27, 18311841, doi:10.5194/angeo-27-1831-2009, 2009.

Lui, A. T. Y.: Current disruption in the Earth's magnetosphere: Observations and models, J. Geophys. Res., 101, 13067-13088, 1996.

Lui, A. T. Y.: Potential plasma instabilities for substorm expansion onsets, Space Sci. Rev., 113, 127-206, 2004. 
Lui, A. T. Y.: Comment on "Tail reconnection triggering substorm onset", Science, 324, 5933, doi:10.1126/science.1167726, 2009.

Lui, A. T. Y., Mankofsky, A., Chang, C.-L., Papadopoulos, K., and Wu, C. S.: A current disruption mechanism in the neutral sheet: A possible trigger for substorm expansions, Geophys. Res. Lett., 17, 745-748, 1990.

Lui, A. T. Y., Chang, C.-L., Mankofsky, A., Wong, H.-K., and Winske, D.: A cross-field current instability for substorm expansions, J. Geophys. Res., 96, 11389-11401, 1991.

Lui, A. T. Y., Lopez, R. E., Anderson, B. J., Takahashi, K., Zanetti, L. J., McEntire, R. W., Potemra, T. A., Klumpar, D. M., Greene, E. M., and Strangeway, R.: Current disruptions in the near-Earth neutral sheet region, J. Geophys. Res., 97, 1461-1480, 1992.

McFadden, J. P., Carlson, C. W., Larson, D., Bonnell, J., Mozer, F., Angelopoulos, V., Glassmeier, K.-H., and Auster, U.: THEMIS ESA First Science Results and Perfomance Issues, Space Sci. Rev., 141, 477-508, 2008.

Moldwin, M. B. and Hughes, W. J.: Plasmoids as magnetic flux ropes, J. Geophys. Res., 96, 14051-14064, 1991.

Moldwin, M. B. and Hughes, W. J.: Observations of Earthward and tailward propagating flux rope plasmoids: Expanding the plasmoid model of geomagnetic substorms, J. Geophys. Res., 99, 183-198, 1994.

Nakamura, R., Baumjohann, W., Schödel, R., Brittnacher, M., Sergeev, V. A., Kubyshkina, M., Mukai, T., and Liou, K.: Earthward flow bursts, auroral streamers, and small expansions, J. Geophys. Res., 106, 10791-10802, 2001.

Ohtani, S., Takahashi, K., Zanetti, L. J., Potemra, T. A., McEntire, R. W., and Iijima, T.: Initial signatures of magnetic field and energetic particle fluxes at tail reconfiguration - Explosive growth phase, J. Geophys. Res., 97, 19311-19324, 1992.

Pu, Z. Y., Chu, X. N., Cao, X., Mishin, V., Angelopoulos, V., Wang, J., Wei, Y., Zong, Q.-G., Fu, S. Y., Xie, L., Glassmeier, K.-H., Frey, H., Russell, C. T., Liu, J., McFadden, J., Larson, D., Mende, S., Mann, I., Sibeck, D., Sapronova, L. A., Tolochko, M. V., Saifudinova, T. I., Yao, Z. H., Wang, X. G., Xiao, C. J., Zhou, X.-Z., Reme, H., and Lucek, E.: THEMIS observations of substorms on 26 February 2008 initiated by magnetotail reconnection, J. Geophys. Res., 115, A02212, doi:10.1029/2009JA014217, 2010.

Roux, A., Contel, O. L., Coillot, C., Bouabdellah, A., de La Porte, B., Alison, D., Ruocco, S., and Vassal, M. C.: The Search Coil Magnetometer for THEMIS, Space Sci. Rev., 141, 265-275, 2008.

Runov, A., Angelopoulos, V., Sitnov, M. I., Sergeev, V. A., Bonnell, J., McFadden, J. P., Larson, D., Glassmeier, K.H., and Auster, U.: THEMIS observations of an earthwardpropagating dipolarization front, Geophys. Res. Lett., 36, L14106, doi:10.1029/2009GL038980, 2009.

Sergeev, V., Angelopoulos, V., Apatenkov, S., Bonnell, J., Ergun, R., Nakamura, R., McFadden, J., Larson, D., and Runov, A.: Kinetic structure of the sharp injection/dipolarization front in the flow-braking region, Geophys. Res. Lett., 36, L21105, doi:10.1029/2009GL040658, 2009.

Shiokawa, K., Baumjohann, W., and Haerendel, G.: Breaking of high-speed flows in the near-Earth tail, Geophys. Res. Lett., 24, 1179-1182, 1997.

Shiokawa, K., Baumjohann, W., Haerendel, G., Paschmann, G., Fennell, J. F., Friis-Christensen, E., Lühr, H., Reeves, G. D.,
Russell, C. T., Sutcliffe, P. R., and Takahashi, K.: High-speed ion flow, substorm current wedge, and multiple Pi 2 pulsations, J. Geophys. Res., 103, 4491-4507, 1998.

Shiokawa, K., Miyashita, Y., Shinohara, I., and Matsuoka, A.: Decrease in $B_{\mathrm{Z}}$ prior to the dipolarization in the near-Earth plasma sheet, J. Geophys. Res., 110, A09219, doi:10.1029/2005JA011144, 2005.

Slavin, J. A., Lepping, R. P., Gjerloev, J., Fairfield, D. H., Hesse, M., Owen, C. J., Moldwin, M. B., Nagai, T., Ieda, A., and Mukai, T.: Geotail observations of magnetic flux ropes in the plasma sheet, J. Geophys. Res., 108, A11015, doi:10.1029/2002JA009557, 2003.

Speiser, T. W.: Particle trajectories in model current sheets, J. Geophys. Res., 70, 4219-4226, 1965.

Speiser, T. W.: Particle motion in the tail current sheet, Adv. Space Res., 11, 151-159, 1991.

Tsyganenko, N. A.: Modeling the Earth's magnetospheric magnetic field confined within a realistic magnetopause, J. Geophys. Res., 100, doi:10.1029/94JA03193, 1995.

Vaivads, A., Khotyaintsev, Y., André, M., and Treumann, R. A.: Plasma Waves Near Reconnection Sites, Lect. Notes Phys., 687, 251-269, 2006.

Walsh, A. P., Fazakerley, A. N., Wilson, R. J., Alexeev, I. V., Henderson, P. D., Owen, C. J., Lucek, E., Carr, C., and Dandouras, I.: Near-simultaneous magnetotail flux rope observations with Cluster and Double Star, Ann. Geophys., 25, 1887-1897, doi:10.5194/angeo-25-1887-2007, 2007.

Zhang, H., Pu, Z. Y., Cao, X., Fu, S. Y., Liu, Z. X., Ma, Z. W., Dunlop, M. W., Baumjohann, W., Xiao, C. J., Hong, M. H., Cao, J. B., Zong, Q. G., Wang, X. G., Carr, C., Rème, H. A., Dandouras, I., Fazakerley, A., Frey, H. U., and Escoubet, C. P.: TC-1 observations of flux pileup and dipolarization-associated expansion in the near-Earth magnetotail during substorms, Geophys. Res. Lett., 34, L03104, doi:10.1029/2006GL028326, 2007.

Zhou, X.-Z., Angelopoulos, V., Runov, A., Sitnov, M. I., Zong, Q.G., and Pu, Z. Y.: Ion distributions near the reconnection sites: Comparison between simulations and THEMIS observations, J. Geophys. Res., 114, A12211, doi:10.1029/2009JA014614, 2009a.

Zhou, M., Ashour-Abdalla, M., Deng, X., Schriver, D., ElAlaoui, M., and Pang, Y.: THEMIS observation of multiple dipolarization fronts and associated wave characteristics in the near-Earth magnetotail, Geophys. Res. Lett., 36, L20107, doi:10.1029/2009GL040663, 2009b.

Zhou, X.-Z., Angelopoulos, V., Sergeev, V. A., and Runov, A.: Accelerated ions ahead of earthward propagating dipolarization fronts, J. Geophys. Res., 115, A00I03, doi:10.1029/2010JA015481, 2010.

Zhou, X.-Z., Angelopoulos, V., Sergeev, V. A., and Runov, A.: On the nature of precursor flows upastream of advancing dipolarization fronts, J. Geophys. Res., 116, A03222, doi:10.1029/2010JA016165, 2011.

Zong, Q.-G., Fritz, T. A., Pu, Z. Y., Fu, S. Y., Baker, D. N., Zhang, H., Lui, A. T., Vogiatzis, I. I., Glassmeier, K.-H., Korth, A., Daly, P. W., Balogh, A., and Rème, H.: Cluster observations of Earthward flowing plasmoid in the tail, Geophys. Res. Lett., 31, L18803, doi:10.1029/2004GL020692, 2004. 